\title{
How does in-company training influence knowledge, competence and performance?
}

\section{KRISTINA SISYUK}

Human capital theorization, company practice and political, economic and social agendas emphasize the importance of lifelong learning and training in the workplace. Acquisition of human capital does not end with education in school, at university or in apprenticeship programs, companies also invest in further training of their employees.

This research analyzes available theories on investment in in-company training, knowledge and competence formation, and on performance of employees in the workplace as well as to review empirical relations between these four variables in 269 empirical studies from more than 60 countries performed between 1962 and 2018 .

The findings show that the theoretical and methodological diversity of analyzed theories and empirical studies is quite large yet still limited. Numerous scientists have tried to explain relations between "training" and "employee performance" and to operationalize the latter. However, the relations and interdependencies between in-company training, knowledge, competence and performance of employees in the workplace have rarely, if ever, been explored thus far, and the economic efficiency of in-company training as well as the role of mediating variables continues to be an empirical question.

The results of this first stage will be used to develop a theoretical framework for empirical research on the relationship between in-company training and performance of employees in the workplace by utilizing the mediating role of employees' knowledge and competence.

Key words: Human Capital, Training, Knowledge, Competence, Performance 